\title{
Restriction Enzyme-Mediated Integration Used to Produce Pathogenicity Mutants of Colletotrichum graminicola
}

\author{
M. R. Thon, E. M. Nuckles, and L. J. Vaillancourt \\ Department of Plant Pathology, S-305 Agricultural Sciences Center-North, University of Kentucky, Lexington \\ 40546-0091, U.S.A. \\ Accepted 29 August 2000.
}

\begin{abstract}
We have developed a restriction enzyme-mediated insertional mutagenesis (REMI) system for the maize pathogen Colletotrichum graminicola. In this report, we demonstrate the utility of a REMI-based mutagenesis approach to identify novel pathogenicity genes. Use of REMI increased transformation efficiency by as much as 27-fold over transformations with linearized plasmid alone. Ninetynine transformants were examined by Southern analysis, and $51 \%$ contained simple integrations consisting of one copy of the vector integrated at a single site in the genome. All appeared to have a plasmid integration at anique site. Sequencing across the integration sites of six transformants demonstrated that in all cases the plasmid integration occurred at the corresponding restriction enzymerecognition site. We used an in vitro bioassay to identify two pathogenicity mutants among 660 transformants. Genomic DNA flanking the plasmid integration sites was used to identify corresponding cosmids in a wild-type genomic library. The pathogenicity of one of the mutants was restored when it was transformed with the cosmids.
\end{abstract}

Additional keywords: anthracnose leaf blight, anthracnose stalk rot, corn, Glomerella graminicola.

Colletotrichum graminicola (Ces.) G.W. Wils. causes anthracnose stalk rot and anthracnose leaf blight in maize. These diseases have become increasingly prevalent in the United States during the last 25 years. Anthracnose stalk rot is the most damaging of the two disease phases, and it is considered to be one of the most common and economically important of the fungal stalk rots of maize (White 1999). Despite the fact that $C$. graminicola is an ubiquitous pathogen with significant destructive potential (Bergstrom and Nicholson 1999), little is known about the fungal characters that are important for pathogenicity and aggressiveness of $C$. graminicola on maize stalks.

Random mutagenesis studies historically have been effective for investigations of complex biological processes such as pathogenicity. A transformation technique known as restriction enzyme-mediated integration of plasmid DNA, or REMI, can be used to generate random insertional mutations in plant

Corresponding author: L. J. Vaillancourt; Telephone: +1-859-257-2203; E-mail: vaillan@pop.uky.edu pathogenic fungi (Kahmann and Basse 1999; Maier and Shäfer 1999). In a REMI transformation, a restriction enzyme is introduced into the transformation mix. By a process that is poorly understood, the enzyme gains access to the genomic DNA in the nucleus of the transformation recipient and introduces double-stranded breaks at its recognition sites. These breaks are recombinogenic with the transforming plasmid DNA that has been linearized with the same restriction enzyme. In theory, integration of plasmid DNA into a gene at a restriction site will cause a mutation, and that mutation will be tagged by the integrated plasmid.

The REMI technique is similar to transposon tagging techniques that are available for other organisms and offers some of the same advantages. A restriction enzyme that does not cut within the integrated plasmid can be used to rescue it, along with some of the flanking genomic DNA, creating a plasmid that will replicate in Escherichia coli. The flanking DNA can be sequenced and used to isolate cosmids or plasmids from a library, and the rescued plasmid can be introduced back into the recipient organism where homologous recombination should recreate the original mutant phenotype, confirming that the tagged gene is important for a given function.

We initiated a REMI mutagenesis project with the goal of identifying genes that play important roles in establishing and/or maintaining pathogenic infections of $C$. graminicola in maize stalks. Using a bioassay for pith colonization and necrosis, we screened 660 REMI transformants and identified two strains that had reproducible pathogenicity defects in vitro. These strains also had markedly reduced aggressiveness to maize stalks and leaves in vivo. At least one of the mutations is likely to have been caused by the integration of the transforming plasmid, a conclusion that is based on our ability to complement the mutant with cosmid DNA isolated from a library by using rescued genomic DNA flanking the integrated by using plasmid as a probe. This work establishes the feasibility of a REMI approach for isolating pathogenicity mutants of C. graminicola.

\section{RESULTS}

REMI increased the transformation efficiency of $C$. graminicola up to 27-fold.

The type of plasmid (circular or linear) and the type and amount of restriction enzyme have been reported to affect the 
outcome of REMI transformation (Kahmann and Basse 1999; Maier and Schäfer 1999). We tested the effect of these variables on the transformation efficiency of $C$. graminicola with plasmid pCB1636, which confers hygromycin resistance (Fig. 1). Transformation efficiency was typically low (approximately three transformants per microgram of DNA) when circular or linearized plasmid was used in the absence of a restriction enzyme (Table 1). The largest increases were observed when a linearized plasmid was used and when the enzyme used to cut the plasmid was the same as that added to the transformation mix. When a restriction enzyme other than that used to digest the plasmid was added, the increase in transformation efficiency was only three- to fivefold. We observed a similar small increase in transformation efficiency when restriction enzymes were used in conjunction with a circular plasmid. We evaluated REMI transformation with eight different restriction enzymes: three that produce $5^{\prime}$ overhangs, three that produce $3^{\prime}$ overhangs, and two that produce blunt ends. The addition of a restriction enzyme to the transformation mix generally increased the transformation effi-

Table 1. Transformation efficiency of Colletotrichum graminicola using different enzyme-plasmid combinations

\begin{tabular}{lcccc}
\hline & \multicolumn{4}{c}{ Enzyme added to transformation mix $^{\mathbf{a}}$} \\
\cline { 2 - 5 } Plasmid treatment & None & HindIII & EcoRI & Bam HI \\
\hline Circular & $3.0^{\mathrm{b}}$ & 5.3 & 25.3 & 12.3 \\
& 3.7 & 5.7 & 10.3 & 19.7 \\
Bam HI linearized & $\mathbf{3 . 4}^{\mathrm{c}}$ & $\mathbf{5 . 5}$ & $\mathbf{1 7 . 8}$ & $\mathbf{1 6 . 0}$ \\
& 1.3 & 5.3 & 3.6 & 62.7 \\
& 5.0 & 22.7 & 26.3 & 112.3 \\
Hin dIII linearized & $\mathbf{3 . 2}$ & $\mathbf{1 4 . 0}$ & $\mathbf{1 5 . 0}$ & $\mathbf{8 7 . 5}$ \\
& 0.3 & 22.3 & 13.0 & 19.3 \\
& 5.3 & 28.0 & 7.3 & 15.0 \\
& $\mathbf{2 . 8}$ & $\mathbf{2 5 . 2}$ & $\mathbf{1 0 . 2}$ & $\mathbf{1 7 . 2}$ \\
\hline
\end{tabular}

${ }^{a}$ For all enzyme treatments, 40 units of enzyme were added to the transformation mix.

${ }^{b}$ Number of transformants per microgram of DNA.

${ }^{\mathrm{c}}$ Numbers in bold represent the averages of two experiments.

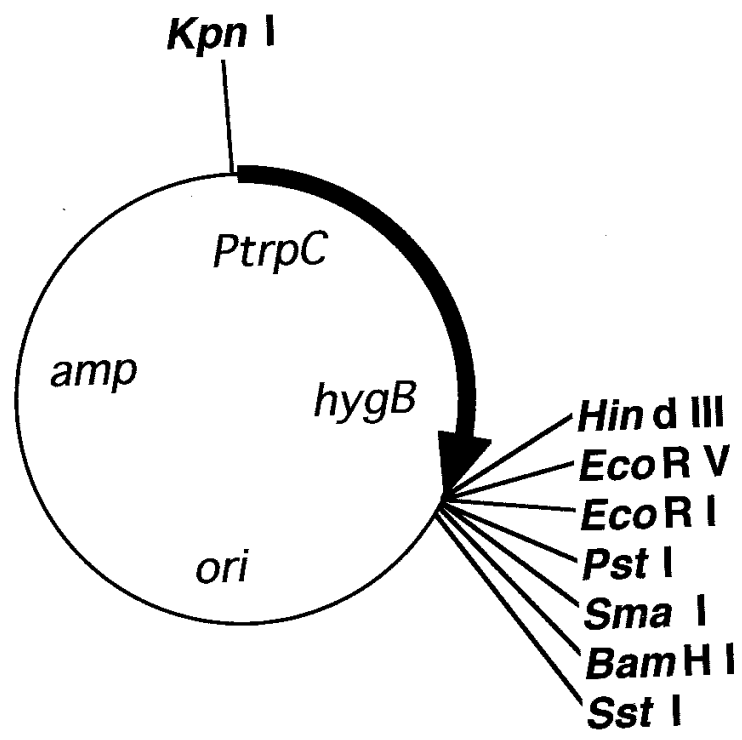

Fig. 1. Map of plasmid pCB1636 (Sweigard et al. 1997). ori $=$ plasmid origin of replication. amp $=$ ampicillin resistance gene. PtrpC $=$ Aspergillus nidulans $\operatorname{trp} C$ promoter. hyg $B=$ bacterial hygromycin B phosphotransferase gene. ciency. The restriction enzyme quantity needed to achieve the optimum gain in transformation efficiency varied depending on which restriction enzyme was used (Table 2). We obtained the highest transformation efficiencies with 60 units of HindIII or 20 units of BamHI.

Twenty-three single-spored transformants were maintained on potato dextrose agar (PDA) (Difco Laboratories, Detroit, MI, U.S.A.) without hygromycin for 8 weeks, with transfers to fresh medium every 2 weeks. All of the transformants retained their resistance to hygromycin during the course of this experiment.

\section{Treatment with restriction enzymes had no effect on protoplast survival.}

Restriction enzymes that produced $3^{\prime}$ overhangs consistently resulted in lower transformation efficiencies than enzymes that produced $5^{\prime}$ overhangs (Table 2). We postulated that breaks in the genomic DNA that result in $3^{\prime}$ overhangs might be less efficiently repaired than other types of DNA breaks. We performed an experiment to determine the effect of restriction enzymes alone on protoplast survival. A procedure identical to the transformation protocol was used, except that no plasmid DNA was included in the transformation mix.

Table 2. Effect of addition of varying quantities of restriction enzymes on transformation efficiency of Colletotrichum graminicola

\begin{tabular}{|c|c|c|c|c|c|}
\hline \multirow[b]{2}{*}{ Enzyme $^{a}$} & \multirow{2}{*}{$\begin{array}{c}\text { Overhang at } \\
\text { cleavage site }\end{array}$} & \multicolumn{4}{|c|}{$\begin{array}{c}\text { Units of enzyme added to transforma- } \\
\text { tion mix } \\
{\text { (transformation efficiency })^{\mathbf{b}}}^{\text {(trotions }}\end{array}$} \\
\hline & & $\mathbf{0}$ & 20 & 40 & 60 \\
\hline \multirow[t]{4}{*}{ EcoRI } & $5^{\prime}$ & $2.3^{\mathrm{c}}$ & 17.3 & 32.3 & 47.0 \\
\hline & & 6.0 & 40.7 & 48.7 & 50.3 \\
\hline & & 0.3 & 1.0 & 1.6 & 1.3 \\
\hline & & $2.9^{\mathrm{d}}$ & 19.7 & 27.5 & 32.9 \\
\hline \multirow[t]{4}{*}{ BamHI } & $5^{\prime}$ & 4.3 & 66.3 & 27.7 & 39.7 \\
\hline & & 3.3 & 39.0 & 50.3 & 49.7 \\
\hline & & 2.3 & 36.7 & 27.7 & 9.3 \\
\hline & & 3.3 & 47.3 & 35.2 & 32.9 \\
\hline \multirow[t]{4}{*}{ HindIII } & $5^{\prime}$ & 4.0 & 60.6 & 60.3 & 77.3 \\
\hline & & 1.7 & 18 & 20.3 & 25.6 \\
\hline & & 1.7 & 37.3 & 49.7 & 55.7 \\
\hline & & 2.5 & 38.6 & 43.4 & 52.9 \\
\hline \multirow{4}{*}{ Pst $\mathrm{I}$} & $3^{\prime}$ & 0 & 7.6 & 2.0 & 1.3 \\
\hline & & 1.3 & 12.7 & 6.7 & 2.0 \\
\hline & & 3.7 & 35.0 & 23.3 & 17.3 \\
\hline & & 1.7 & 18.4 & 10.7 & 6.9 \\
\hline \multirow{4}{*}{ KpnI } & $3^{\prime}$ & 0 & 0 & 0 & 0 \\
\hline & & 1.3 & 1.7 & 1.0 & 1.7 \\
\hline & & 3 & 1.3 & 1.3 & 1.3 \\
\hline & & 1.4 & 1.0 & 0.8 & 1.0 \\
\hline \multirow[t]{4}{*}{ Sst $\mathrm{I}$} & $3^{\prime}$ & 1.0 & 3.7 & 4.3 & 3.3 \\
\hline & & 2.3 & 20.3 & 18.0 & 5.7 \\
\hline & & 1.7 & 33.7 & 25.7 & 13.0 \\
\hline & & 1.7 & 19.2 & 16.0 & 7.3 \\
\hline \multirow[t]{4}{*}{ EcoRV } & Blunt & 0.3 & 0.3 & 1.0 & 1.0 \\
\hline & & 2.0 & 8.7 & 7.3 & 5.3 \\
\hline & & 1.3 & 11.7 & 19.0 & 11.7 \\
\hline & & 1.2 & 6.9 & 9.1 & 6.0 \\
\hline \multirow[t]{4}{*}{ SmaI } & Blunt & 1.7 & 7.3 & 9.7 & 16.3 \\
\hline & & 2.7 & 26.3 & 28.3 & 28.0 \\
\hline & & 3.3 & 23.7 & 42.0 & 42.3 \\
\hline & & 2.6 & 19.1 & 26.7 & 28.9 \\
\hline
\end{tabular}

\footnotetext{
a Plasmid pCB1636 was linearized using the enzyme indicated.

${ }^{\mathrm{b}}$ Number of transformants per microgram of DNA.

${ }^{c}$ Values for three experiments are listed.

${ }^{\mathrm{d}}$ Numbers in bold represent the averages of three experiments.
} 
Serial dilutions of treated protoplasts in polyethylene glycol (PEG) solution were plated in regeneration agar without hygromycin. After incubation at room temperature for 3 days, the number of colonies on each dilution plate was recorded. We found no significant differences in the number of colonies after treatment with 0, 20, 40, or 60 units of EcoRI, BamHI or PstI (data not shown).

\section{More than half of the REMI transformants analyzed had single-copy integrations of the plasmid DNA.}

We used Southern hybridization analysis to examine 99 randomly selected transformants that were generated by vari-

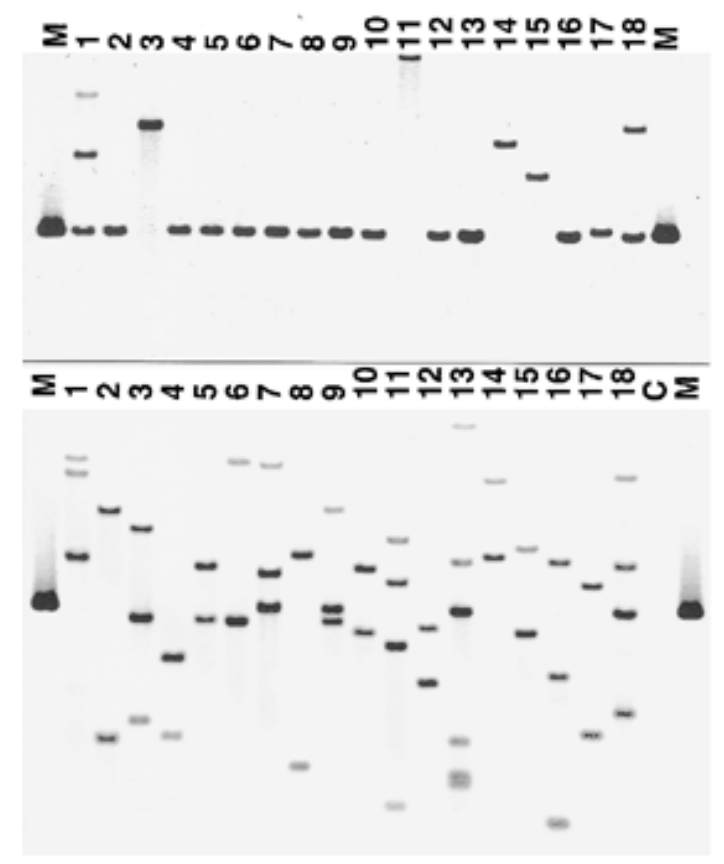

Fig. 2. Southern hybridization of transformants derived from restriction enzyme-mediated integration of plasmid DNA using PstI (lanes 1 to 8) or BamHI (lanes 9 to 18). Lanes labeled M contain linearized pCB1636 $(4.3 \mathrm{~kb})$, which was used as a size marker. Genomic DNA in the upper blot was digested with either PstI (lanes 1 to 8) or BamHI (lanes 9 to 18). DNA in the lower blot was digested with KpnI. Both blots were probed with pCB1636. Plasmid integrations were interpreted as follows: type A, 2, 4, 5, 6, 8, 10, 12, 17; type B, 14; type C, 1, 3, 7, 9, 11, 13, 16, 18. Transformants 1 and 18 have multiple, dispersed integrations, indicated by the presence of multiple bands (left). Transformants 7, 9, and 13 have tandem integrations, indicated by the $4.3-\mathrm{kb}$ band (the same size as pCB1636) present for these transformants (right). ous enzyme combinations (Table 3 and Fig. 2). Of the 99 transformants, only 18 contained classic REMI integrations in which a single copy of the plasmid was inserted with the restriction sites present at both plasmid and genomic DNA junctions (type A) (Fig. 3A). Thirty-two others had singlecopy integrations in which one or both of the restriction sites at the plasmid-genomic DNA junctions had been lost (type B) (Fig. 3A). The remaining 49 transformants had multiple, dispersed integrations; tandem integrations at a single locus; some form of rearrangement of the integrated plasmid; or a combination of these (type C) (Fig. 3A). Each of the 99 transformants had a unique restriction pattern, indicating that each contained a plasmid integration at a different site. The specific enzyme used for the transformation did not significantly affect the proportion of type $\mathrm{A}, \mathrm{B}$, or $\mathrm{C}$ transformants that were recovered (Table 3 ). It is notable, however, that none of the 32 transformants produced by a linearized plasmid or mismatched enzymes contained type A integrations.

\section{Fungal genomic DNA flanking integrated plasmids could be rescued.}

The most desirable integration event for subsequent analysis is to insert one copy of the plasmid at a single, random point in the genome (type A or B). Such integrations are comparatively simple to recover with a restriction enzyme that does not digest the plasmid DNA. Fifty-one percent of the transformants that we generated were of this type. The remainder contained complex integrations (type C) that are less easy to analyze genetically and, reportedly, difficult to rescue (Kahmann and Basse 1999). Typically mutants with complex integrations are discarded and more tractable mutants are sought. We identified three type $\mathrm{C}$ transformants with very interesting phenotypes, however, which we were reluctant to abandon, so we attempted to rescue these more complex integrations.

Southern hybridization analysis indicated that each transformant contained several tandemly arranged copies of the transforming plasmid at a single locus. Plasmid rescue attempts using MluI or BglII, enzymes that do not cut within the vector, resulted in plasmids that contained complex rearrangements or deletions of portions of the original transforming plasmid. Southern blots indicated that these rearrangements were not present in the genomes of the transformants, which means they probably occurred during replication of the rescued plasmids in E. coli. We then employed a strategy to recover the two flanking regions separately. Genomic DNA from each type $\mathrm{C}$ transformant was digested with enzymes that contained single recognition sites in the vector (Fig. 3B).

Table 3. Plasmid integration events that occurred using various plasmid-restriction enzyme combinations

\begin{tabular}{|c|c|c|c|c|c|c|c|}
\hline \multirow[b]{2}{*}{ Plasmid treatment } & \multirow[b]{2}{*}{ Enzyme used in transformation } & \multirow[b]{2}{*}{ Transformants assayed } & \multicolumn{5}{|c|}{ Type of integration } \\
\hline & & & $\mathbf{A}$ & B & $\mathbf{C}$ & $\mathbf{C}_{\mathrm{t}}^{\mathrm{a}}$ & $\mathbf{C}_{\mathrm{m}}$ \\
\hline EcoRI & EcoRI & 9 & 1 & 2 & 6 & 1 & 1 \\
\hline BamHI & BamHI & 10 & 3 & 3 & 4 & 1 & 1 \\
\hline HindIII & HindIII & 20 & 5 & 7 & 8 & 2 & 2 \\
\hline PstI & PstI & 8 & 4 & 1 & 3 & 1 & 1 \\
\hline Sst $\mathrm{I}$ & SstI & 11 & 2 & 1 & 8 & 6 & 3 \\
\hline EcoRV & EcoRV & 9 & 3 & 2 & 4 & 0 & 0 \\
\hline BamHI & None & 12 & 0 & 3 & 9 & 5 & 7 \\
\hline HindIII & EcoRI & 10 & 0 & 8 & 2 & 0 & 2 \\
\hline HindIII & BamHI & 10 & 0 & 5 & 5 & 3 & 4 \\
\hline
\end{tabular}

${ }^{a}$ Type $C$ transformants are subdivided into those with tandem integrations $\left(C_{t}\right)$ and those with multiple integrations $\left(C_{m}\right)$. 
The rescue of DNA from both flanks of the plasmid integration site was accomplished, in most cases, by digesting the genomic DNA separately with KpnI or XbaI. The genomic DNA was religated and transformed into E. coli. As expected, a mixture of two plasmid types resulted. One type was derived from internal repeats of the tandemly duplicated plasmid array within the fungal genome, whereas the other contained flanking genomic DNA (25 to $100 \%$ of the plasmids in each experiment contained the desired flanking DNAs).

\section{Plasmid integrations occurred at the recognition site of the restriction enzyme used for REMI.}

We wanted to determine whether REMI integrations typically occurred, as predicted by theory, at the recognition site of the restriction enzyme used in the transformation as well as whether deletions of genomic DNA at the plasmid integration sites were common. To test these possibilities, we sequenced the genomic DNA at the plasmid integration sites in several REMI transformants. In addition to the three type $\mathrm{C}$ transformants mentioned above, we also rescued flanking genomic DNA from one type A transformant and two type B transformants with either BglII or $M l u I$. The plasmid-genomic DNA junctions were sequenced in each case, and polymerase chain reaction (PCR) primers were designed based on the sequence to amplify the corresponding region from wild-type (strain M1.001) DNA.

Neither plasmid nor genomic DNA sequences had been deleted in the type A transformant. Furthermore, the plasmid integration occurred at the recognition site of the enzyme used during REMI transformation. A 135-bp fragment of DNA was deleted from the plasmid at the plasmid-genomic DNA junction of one type B transformant, although the genomic sequence at the integration site of this transformant was intact. As in the type A transformant, the integration occurred at the recognition site of the enzyme used for transformation. The sequence of the rescued plasmid from the second type B transformant indicated that $6 \mathrm{bp}$ of plasmid DNA had been deleted. The primers that were developed using the sequence of the rescued genomic DNA failed to amplify the expected PCR product, suggesting that a large deletion of the genomic DNA may have occurred at the plasmid integration site in this transformant. The sequence of the rescued genomic DNA, however, was consistent with an integration event at the recognition site of the enzyme used for transformation.

Similar analyses were performed on the three type $\mathrm{C}$ transformants, although in one case cosmid clones from a genomic DNA library were used in place of PCR products from the wild-type DNA. In one type $\mathrm{C}$ transformant, a single base pair was deleted from the genomic DNA at the integration site, whereas in the other two transformants integration occurred without any loss of genomic DNA. In all three transformants, plasmid integration events occurred at the recognition sites of the enzymes used for transformation. Thus, in all six of the REMI transformants analyzed, integration of the REMI plasmid occurred at the recognition site of the REMI enzyme. In only one case did there appear to be a significant deletion of genomic DNA at the site of plasmid integration.

\section{Plasmid integrations in REMI transformants were meiotically unstable.}

One way to discover whether a mutation is tagged in a REMI transformant is to cross the transformant with a wild- type strain and determine whether the integrated plasmid and the mutant phenotype cosegregate. To discern whether an integrated plasmid DNA segregated normally in a cross, a randomly selected type A transformant was mated with M5.001, a compatible wild-type strain, using standard methods (Vaillancourt and Hanau 1991). The resulting progeny were screened for hygromycin resistance and for the presence of plasmid pCB1636. Of the 47 progeny assayed, none were resistant to hygromycin. Southern analysis demonstrated, however, that three of the 47 contained plasmid DNA, suggesting that these progeny contained nonfunctional forms of the hygromycin phosphotransferase gene construct. An unlinked restriction fragment length polymorphism marker (Vaillancourt et al. 2000) segregated as expected (1:1) among these progeny, suggesting that there was nothing abnormal about the cross itself (data not shown).

A type C transformant was also crossed with M5.001. Nine of the 15 progeny analyzed were hygromycin resistant, and Southern hybridization confirmed that plasmid DNA was present in these progeny and absent in the wild-type progeny. Southern blots also revealed that three of the nine hygromycin-resistant progeny contained only a single copy of the plasmid, whereas the type $\mathrm{C}$ parent and remaining hygromycin-resistant progeny contained two or more tandemly repeated copies of the plasmid.

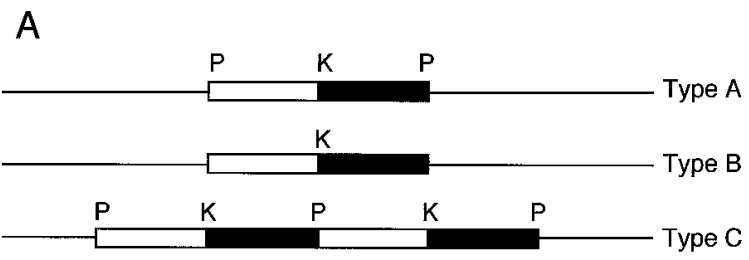

B
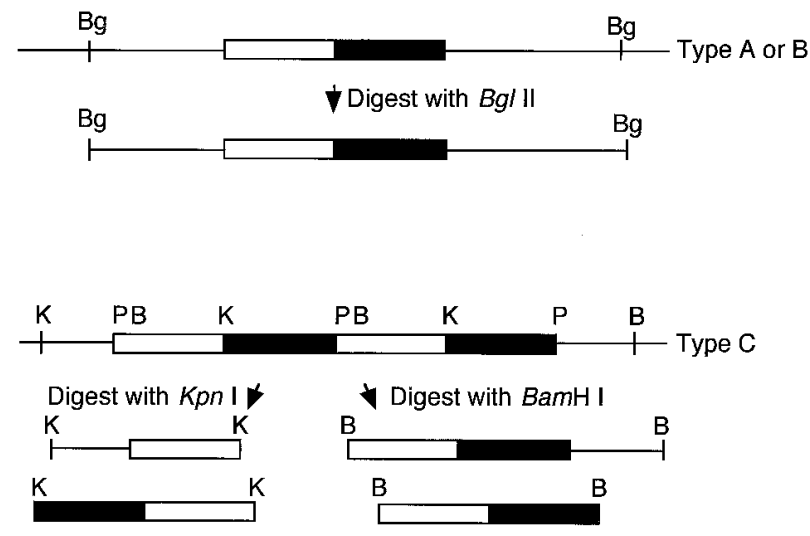

Fig. 3. Plasmid integration types and plasmid rescue strategies of transformants obtained with restriction enzyme-mediated integration. A, Types of plasmid integrations. Note that type $\mathrm{C}$ transformants include those with tandemly repeated plasmid copies (shown) as well as multiple dispersed copies (not shown). B, Plasmid rescue strategies. Type A and B transformants can be rescued by cutting with a single restriction enzyme that has no recognition site within the plasmid. Flanking DNA from type C transformants with tandemly repeated plasmid copies can be rescued by cutting with each of two restriction enzymes with single recognition sites within the plasmid. Bars represent the plasmid DNA; the white part of the bar represents the portion of the plasmid DNA that is required for replication in Escherichia coli. $\mathrm{P}=P s t \mathrm{I} . \mathrm{K}=K p n \mathrm{I} . \mathrm{Bg}=B g l \mathrm{II} . \mathrm{B}=$ Bam $\mathrm{HI}$. 


\section{Two pathogenicity mutants were identified among 660 transformants.}

Our screening strategy uses a rapid assay to identify potential pathogenicity mutants followed by replicated experiments to confirm the mutant phenotype. We used the rapid in vitro assay to identify stalk rot mutants, identifying 41 potential mutants and subjected each of them to replicated in vitro assays. Two transformants (strains 6-2 and 9-4) were consistently reduced in their ability to colonize or cause necrosis of maize internode tissues (Fig. 4A to E). Experiments in vivo confirmed the mutant phenotype. In contrast to the wild-type control, neither mutant colonized intact maize stalks and one (strain 6-2) caused no detectable stalk discoloration in the in vivo experiments (data not shown). Both mutants were tested for pathogenicity to seedling leaves of maize cultivar Mo940, an inbred that is highly susceptible to the wild-type strain M1.001 (Fig. 4F to G). Strain 6-2 caused no symptoms on the leaves (Fig. 4H), whereas strain 9-4 caused only a few, very small lesions (Fig. 4I).

\section{Molecular characterization of strains 6-2 and 9-4.}

Strain 6-2 was isolated in an experiment in which EcoRI was used as the REMI enzyme. Southern blots of genomic DNA from strain 6-2 indicated that this transformant contains one complete copy of the plasmid as well as an adjacent incomplete copy in a reverse orientation. We used NotI-digested genomic DNA to rescue plasmids containing 713 bp of genomic DNA from one flank of the integration site (plasmid p62notI.1). Attempts to rescue plasmids containing genomic DNA from the other flank were not successful, perhaps because the copy of the vector adjacent to that flank is incomplete. The genomic DNA from p62notI.1 was used as a probe to recover two cosmids from a wild-type genomic library. We then used one of these cosmids as a template to sequence a 1,309 bp region that spanned the plasmid integration site (GenBank accession number AF263837). Analysis of the sequence indicated that the plasmid integration event occurred at an EcoRI site in strain 6-2 and that no deletion of genomic DNA occurred.

We used the genomic sequence to perform a search of the Saccharomyces genome database (available on-line from Stanford University, Stanford, CA, U.S.A.) with the BLASTX program and low-complexity sequence filtering. Sequence YLR066W was the only database entry to produce highscoring segment pairs $\left(E=1.4 \times 10^{-13}\right)$ and encodes a subunit of a signal peptidase complex. An open reading frame (ORF) that displays codon usage bias similar to other $C$. graminicola genes was detected by the computer program CodonUse (C. Halling, Monsanto Co., St. Louis, MO, U.S.A.). The translation start codon for the ORF begins 776 nucleotides upstream of the plasmid integration site and coincides with the start codon of the yeast signal peptidase subunit.

Strain 9-4 was isolated in an experiment in which PstI was used as the REMI enzyme and contained a single integration of two or more tandemly repeated copies of the plasmid. Southern hybridization analysis indicated that the PstI sites between the tandem copies as well as those at the plasmidgenomic DNA junction were intact. The genomic DNA flanking the integrated vector on both sides was isolated by rescuing plasmids derived from either BamHI- or KpnIdigested genomic DNA. The flanking DNA was sequenced and used to design PCR primers. A 611 bp fragment spanning the insertion point was amplified from genomic DNA of wildtype strain M1.001 and sequenced. The sequence matched that of the rescued plasmid, and analysis of the wild-type sequence confirmed that the integration in 9-4 occurred at a PstI site with no deletion of the genomic DNA.

More than $1 \mathrm{~kb}$ of genomic DNA from the region spanning the integration site in strain 9-4 has been sequenced (GenBank accession number AF264878). Two significant matches were found when these sequences were used to search GenBank and the Saccharomyces genome database with the BLASTX program and low-complexity sequence filtering. One match occurred with a group of protein-transport proteins that participate in COPII transport vesicle budding from the endoplasmic reticulum $\left(E=7 \times 10^{-28}\right.$ to $\left.2 \times 10^{-11}\right)$. The other match was with cyclophilin proteins from various sources, including humans, flies, and mice $\left(E=5 \times 10^{-10}\right.$ to $\left.5 \times 10^{-6}\right)$. The two regions of similarity are on opposite sides of the plasmid-insertion site and read in opposite directions. The predicted amino acid sequence alignments indicate that the plasmid integration occurred within a stretch of approximately 500 bp between the two putative genes, which could be an upstream regulatory region for either gene.

We conducted an analysis of predicted ORFs and codon usage bias for the rescued sequences with CodonUse. Both of the putative genes correspond to ORFs and display significant codon bias, suggesting that they may encode functional genes. We also analyzed the sequences surrounding the translation initiation codons of the two putative genes in 9-4. The start position and their context in both cases were similar to those of expressed sequences (Gurr et al. 1987).

\section{Wild-type genomic clones complement the mutation in strain 6-2.}

The rescued genomic DNAs from strains 6-2 and 9-4 were used as probes to identify cosmids from a library of the wildtype strain M1.001 that was constructed in a vector carrying a selectable marker for benomyl resistance (J. Rollins and R. Hanau, unpublished). One cosmid that hybridized to the probes from strain 9-4 was identified and used to transform protoplasts prepared from strain 9-4. Five benomyl- and hygromycin-resistant transformants were tested for pathogenicity on maize internode sections in vitro and on leaves in vivo. None of the transformants produced symptoms that were significantly different from those caused by strain 9-4 (data not shown).

Two overlapping cosmids that hybridized to the probe from strain 6-2 were identified, and each used to transform protoplasts prepared from strain 6-2. Two hygromycin- and benomylresistant transformants were tested for pathogenicity on maize internode segments in vitro and leaves in vivo. In two separate experiments, the transformants colonized and caused symptoms on internode segments that were comparable to those caused by the wild-type strain (Fig. $4 \mathrm{~J}$ to $\mathrm{K}$ ). One transformant produced foliar lesions that were similar to those caused by the wild type (Fig. 4M), whereas the second caused symptoms that were consistently less severe than those caused by the wild type yet were still significantly greater than those caused by the mutant (Fig. 4L).

The two 6-2 cosmid transformants were digested with KpnI, transferred to nylon membranes, and probed with a genomic DNA fragment immediately adjacent to the integration site of 


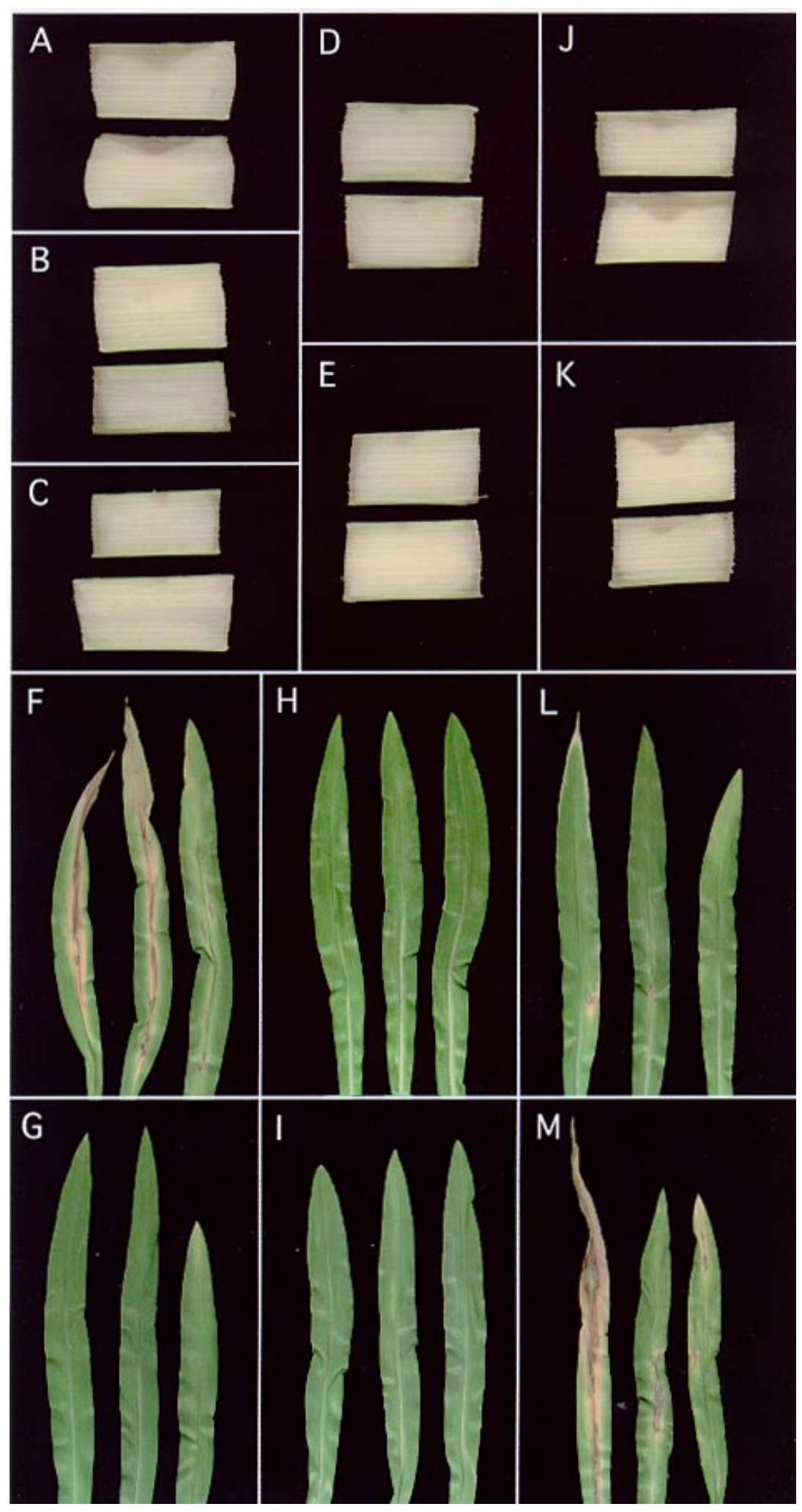

Fig. 4. Inoculation of maize internode segments in vitro and leaves of maize seedlings in vivo with strains of Colletotrichum spp.. The internode segments have been cut longitudinally, and the inoculation site is oriented to the upper-center of each segment. A, M1.001, the wild-type strain. Note the triangular area of discoloration immediately below the inoculation wound. B, Water control. C, Sorghum pathogen C. sublineolum. This species is not a pathogen of maize. D, Strain 6-2. E, Strain 9-4. F, M1.001, the wild-type strain. G, Water control. H, Strain 6-2. I, Strain 9-4. J, Strain 6-2 transformed with cosmid 41H6. K, Strain 6-2 transformed with cosmid 40F5. L, Strain 6-2 transformed with cosmid 41H6. M, Strain 6-2 transformed with cosmid 40F5. 
pCB1636 in strain 6-2. This probe hybridized to a single 6.2$\mathrm{kb}$ band in the wild-type DNA and to a $5.8-\mathrm{kb}$ band in strain 6-2 (Fig. 5). The cosmid transformants contained both the 5.8and the $6.2-\mathrm{kb}$ bands, indicating that these strains contain the disrupted region of DNA present in strain 6-2 as well as a wild-type copy of the sequence on the integrated cosmids.

\section{DISCUSSION}

Although REMI protocols have been described for $C$. graminicola (Epstein et al. 1998) and for other filamentous fungi, detailed analyses of transformation conditions and their effect on plasmid integrations have been reported in only a few cases and, as far as we know, have never been described for C. graminicola. Screening a group of transformants for a loss-of-function phenotype is time consuming, so it is important to ensure that plasmid integrations occur in the predicted manner and that mutagenized genomic sequences can be rescued and characterized once mutants are identified.

The preferred integration event for mutagenesis and plasmid rescue is the insertion of one copy of the plasmid in a single random restriction site of the genome (Kahmann and Basse 1999; Sweigard 1996). Large deletions of genomic DNA occurring in association with REMI transformation are not uncommon, yet can be a serious problem because the DNA contained in the rescued plasmid may not contain the gene responsible for the mutation (Maier and Shäfer 1999; Sweigard 1996; Sweigard et al. 1998). Transformation efficiencies are typically increased significantly by REMI. If they are not, this may indicate that damage caused by the restriction enzyme is not being repaired efficiently and protoplast viability is being compromised. In theory, inefficient DNA repair increases the probability that additional mutations will be unlinked to plasmid integrations (Maier and Shäfer 1999). In consideration of these principles, it is important to test various REMI transformation conditions and determine their effects on transformation efficiency and the percentage of the preferred integration events produced.

The addition of restriction enzymes to $C$. graminicola transformations increased transformation efficiency up to 27-fold. A previous study of $C$. graminicola found only very small increases in transformation efficiency (three- to fivefold) with REMI (Epstein et al. 1998). In this study, however, restriction enzymes were used that did not match the cohesive ends of the linear plasmid. When we performed transformations in this manner, we observed similar small increases in efficiency. Significant increases in transformation efficiency were observed only when the enzyme added to the transformation was the same as that used to linearize the plasmid. Furthermore,

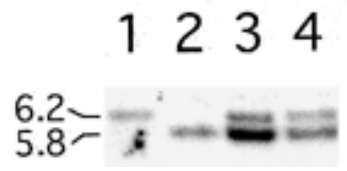

Fig. 5. Southern hybridization of wild-type genomic DNA (lane 1), mutant strain 6-2 (lane 2), strain 6-2 transformed with cosmid 41H6 (lane 3), and strain 6-2 transformed with cosmid 40F5 (lane 4). The DNA in each case was cut with KpnI, which has a single recognition site within the plasmid pCB1636. A rescued 713-bp fragment of genomic DNA that flanks the plasmid integration site in mutant strain 6-2 was used as the probe. transformation of $C$. graminicola in the absence of restriction enzymes or with enzymes that did not match the one used to linearize the plasmid never produced type A transformants. Of the six transformants examined in sufficient detail (one type A, two type B, and three type C), all were the result of plasmid integration events at the REMI restriction enzyme recognition site. These observations support the hypothesis that the enzyme in the transformation mix facilitates integration of DNA that is linearized with the same enzyme through the production of compatible cohesive ends.

When we performed REMI transformation experiments in the absence of DNA and selection pressure, we observed no change in protoplast survival. This suggests that $C$. graminicola is able to efficiently repair breaks in the genomic DNA caused by restriction enzymes. Alternatively, it is possible that restriction enzymes in combination with DNA could have a negative effect on protoplast survival that restriction enzymes alone do not have. It has been suggested that the presence of transforming DNA may be required for entry of restriction enzymes into the nucleus (Maier and Shäfer 1999).

As the number of studies involving REMI increases, it has become clear that the classical REMI event, in which a single copy of the plasmid integrates at a restriction enzyme recognition site leaving both flanking restriction sites intact, does not occur in every case. In REMI experiments with Magnaporthe grisea, Shi et al. (1995) reported that the occurrence of integration events in which the flanking restriction sites remain intact is up to $72 \%$ of transformants with some enzymes. This value included complex transformants with multiple integrations (type C). Classical REMI integrations occurred in approximately $50 \%$ of Ustilago maydis transformants (Bölker et al. 1995), and in C. graminicola, type A REMI integrations occurred less frequently: only $28 \%$ of the time when the same enzyme used for transformation was also used to linearize the transforming DNA (Table 3). Most integration events resulted in the loss of one or both flanking restriction sites, usually as a result of the occurrence of small deletions at the ends of the linearized plasmid DNA. These deletions may result from nuclease digestion of DNA ends during the transformation process or unequal crossovers during plasmid integration at small regions of homology with the ends of the linearized plasmids.

Insertional mutagenesis has been used to identify pathogenicity genes in several other plant-pathogenic filamentous fungi, but not in $C$. graminicola. In an assay of more than 5,000 M. grisea REMI transformants, Sweigard et al. (1998) identified 27 mutants $(0.5 \%)$ with a reproducible pathogenicity defect. Pathogenicity defects occurred in approximately 1 to $2 \%$ of REMI transformants of U. maydis (Bölker et al. 1995). In addition, Sweigard et al. (1998) reported the successful cloning and sequencing of pathogenicity genes identified in this manner. In this study, we identified two transformants with pathogenicity defects out of 660 transformants assayed $(0.3 \%)$.

Because the process of transformation can be mutagenic, untagged mutations may result from the REMI procedure (Kahmann and Basse 1999; Maier and Shäfer 1999; Sweigard et al. 1998). These include deletions, both large and small, and chromosomal rearrangements. Therefore, it is important to confirm that mutations obtained from a REMI experiment are associated with integrated DNA. This can be done by con- 
ducting sexual crosses; rescuing the integrated plasmid and using it to recreate the original mutation by gene disruption; or complementing the mutation with a wild-type copy of the DNA, spanning the plasmid insertion site. Here we demonstrated that the phenotype of mutant strain 6-2 was most likely caused by plasmid integration by complementing it with cosmids that contained the corresponding region from the wildtype strain. We were unable to complement mutant strain 9-4 with a cosmid that was recovered from the library. This may indicate that the REMI integration in this strain is not responsible for the mutant phenotype. Alternatively, it is possible that the entire gene sequence(s) required for complementation of the mutant is not present on the cosmid.

Strain 6-2 is nonpathogenic to maize leaves and stalks in vivo but grows normally in vegetative culture. Our preliminary studies have given no indication of any abnormalities in spore germination or appressorial formation. Further work will focus on characterization of the mutant phenotype and analysis of the structure and function of this gene, the first to be identified as playing a significant role in a fungal stalk rot disease of maize. It is especially intriguing that the same gene product appears to be critical for pathogenicity to stalks and leaves. Genes that confer resistance to $C$. graminicola in maize stalks are not necessarily the same as those that confer resistance to leaf anthracnose (Zuber et al. 1981); thus, it is not clear whether the same host-pathogen interaction occurs in both tissues.

Our work suggests that the analysis of REMI mutants of $C$. graminicola by classical genetic techniques may be problematic as a result of meiotic instability of the integrated plasmid. Such instability has also been reported by others (Epstein et al. 1998). The primary advantage of insertional mutagenesis versus other types of mutagenesis techniques is that the mutation is likely to be tagged with the transforming DNA. If the plasmid and flanking genomic DNA can be rescued together, then the rescued plasmid can be used as a gene-disruption vector to confirm the source of the mutation (Sweigard 1996). Fifty-one percent of transformants have simple integrations that are conducive to plasmid rescue and gene disruption by the rescued plasmid. In other cases, rearrangements of the plasmid during transformation or tandem integration of the vector sequences make rescue of the plasmid with both flanking genomic sequences difficult. We have demonstrated, however, that short regions flanking the plasmid integration can be rescued from more complex transformants. While the short flanking sequences cannot be used directly for gene disruption, they can be used as probes to identify cosmids in a genomic library for use in complementation and gene disruption experiments. These methods can substitute for classical genetic approaches, and so we do not consider meiotic instability of integrated DNA to be a serious impediment to the analysis of $C$. graminicola REMI-derived mutants. This study has also demonstrated the feasibility of the REMI mutagenesis approach for dissection of genetic determinants of pathogenicity of C. graminicola to maize pith and leaf tissues.

\section{MATERIALS AND METHODS}

\section{Fungal strains and culture conditions.}

The $C$. graminicola wild-type strain M1.00 was obtained from R. Hanau (Purdue University, West Lafayette, IN,
U.S.A.). The sexually compatible strain M5.001 was isolated from maize leaves in Brazil (Vaillancourt and Hanau 1994). Conidia of both strains were stored on silica gel (Tuite 1969) and in $7 \%$ dimethylsulfoxide at $-80^{\circ} \mathrm{C}$ (L. Epstein, personal communication). Cultures were inoculated from either of these frozen stocks and maintained on PDA under continuous fluorescent illumination at 25 to $27^{\circ} \mathrm{C}$.

\section{DNA extraction and purification.}

Genomic DNA was purified from C. graminicola stationary cultures grown in $10 \mathrm{ml}$ of Difco (Difco Laboratories, Detroit, MI, U.S.A.) potato dextrose broth in a $60 \times 15-\mathrm{mm}$ petri dish for 5 days at 25 to $27^{\circ} \mathrm{C}$ under continuous fluorescent light. The mycelial mats were collected with sterile toothpicks, blotted briefly on sterile paper towels, and then placed in 15$\mathrm{ml}$ polypropylene centrifuge tubes. The mycelium in each tube was frozen, lyophilized, and crushed to a fine powder with a glass stirring rod. The powdered mycelium was mixed with $1.2 \mathrm{ml}$ of DNA extraction buffer (100 mM Tris, $\mathrm{pH} 7.5 ; 0.7 \mathrm{M}$ $\mathrm{NaCl} ; 10 \mathrm{mM}$ EDTA; and $10 \mathrm{~g}$ of CTAB per liter) per tube, and the mixture was incubated at $65^{\circ} \mathrm{C}$ for $30 \mathrm{~min}$. An equal volume of chloroform was added to each sample, and then the sample was mixed gently. The samples were centrifuged at $3,000 \times g$ for $15 \mathrm{~min}$ at room temperature, the upper aqueous phase was removed to a $1.5-\mathrm{ml}$ Eppendorf tube, and the DNA was precipitated with 0.8 volume of isopropanol. After centrifugation, the pellets were washed with $70 \%$ ethanol, air dried, and dissolved in $100 \mu \mathrm{l}$ of Tris-EDTA (TE) buffer. Two microliters of RNase A solution $(10 \mathrm{mg} / \mathrm{ml})$ was added to each sample, and the samples were stored at $4{ }^{\circ} \mathrm{C}$.

\section{Fungal transformation.}

Falcate conidia were harvested from 3- to 4-week-old cultures of $C$. graminicola strain M1.001 that had been maintained on PDA. The conidia were washed twice by centrifugation with sterile water and resuspended in $100 \mathrm{ml}$ of Fries' medium. The conidial culture was incubated at $30^{\circ} \mathrm{C}$ with gentle shaking. After $48 \mathrm{~h}$, the culture contained numerous oval conidia and very little vegetative growth. The culture was filtered through Nytex membrane (Tetko Inc., Briarcliff, NY, U.S.A.), and the filtrate was centrifuged at $2000 \times g$ for $5 \mathrm{~min}$ at room temperature. The pelleted oval conidia were resuspended at $1.5 \times 10^{8}$ conidia per milliliter in a filter-sterilized solution of $0.7 \mathrm{M} \mathrm{NaCl}$ and $100 \mathrm{mg}$ of Glucanex (Novo Nordisk, Dittengen, Switzerland) per milliliter. The conidial suspension was incubated at $30^{\circ} \mathrm{C}$ with gentle shaking for 4 to $5 \mathrm{~h}$ until the suspension contained predominantly protoplasts that were free of cell walls. The protoplasts were recovered by centrifugation in a Beckman GS-6R centrifuge (Beckman Instruments, Fullerton, CA, U.S.A.) at $2000 \times g$ for $5 \mathrm{~min}$ at $4^{\circ} \mathrm{C}$ and resuspended in $10 \mathrm{ml}$ of STC (1.2 M sorbitol, $10 \mathrm{mM}$

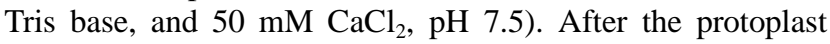
concentration was determined with a hemacytometer, the protoplasts were collected by centrifugation and resuspended in STC at a concentration of $10^{8}$ protoplasts per milliliter. The protoplasts were then frozen in STC at $-80^{\circ} \mathrm{C}$ until use.

Prior to transformation, plasmid pCB1636 was purified with the Qiagen Plasmid MaxiPrep kit (Qiagen Inc., Chatsworth, CA, U.S.A.). The plasmid was linearized by digestion with a restriction enzyme, and the digestion reactions were purified with a Qiaex gel extraction kit (Qiagen Inc.) or 
by extracting once with phenol plus chloroform (1:1) and once with chloroform, precipitating with $1 / 10$ volume of $3 \mathrm{M}$ sodium acetate and 2 volumes of ethanol. After drying, the plasmids were dissolved in TE buffer.

Transformations were performed by combining the protoplasts with $3 \mu \mathrm{g}$ of linearized plasmid DNA dissolved in $10 \mu \mathrm{l}$ of TE buffer in a 50-ml polypropylene centrifuge tube. The mixture was incubated on ice for $20 \mathrm{~min}$, and then 20 to 60 units of restriction enzyme were added to the protoplast mixture immediately before adding $1 \mathrm{ml}$ of a PEG solution (40\% PEG 3,350 wt/vol; $0.6 \mathrm{M} \mathrm{KCl} ; 50 \mathrm{mM} \mathrm{CaCl}$; and $50 \mathrm{mM}$ Tris, $\mathrm{pH}$ $8)$. This mixture was incubated at room temperature for $20 \mathrm{~min}$, combined with $40 \mathrm{ml}$ of regeneration agar (1 M sucrose, $1.25 \%$ casein hydrolysate, $1.25 \%$ yeast extract, $1.5 \%$ agar, and $250 \mu \mathrm{g}$ of hygromycin B per milliliter), and then poured into two petri dishes. The dishes were incubated at $30^{\circ} \mathrm{C}$, and hygromycinresistant colonies were transferred to PDA containing $50 \mu \mathrm{g}$ of hygromycin B (PDA + Hyg) per milliliter after 4 to 5 days. Conidia from these primary transformants were spread onto $2 \%$ water agar containing $50 \mu \mathrm{g}$ of hygromycin B per milliliter, and after $24 \mathrm{~h}$, a single hygromycin-resistant germling was recovered from each transformant and transferred to PDA + Hyg. After 2 weeks of incubation, conidia were harvested from the cultures and stored on silica gel at $-80^{\circ} \mathrm{C}$.

\section{Southern hybridization.}

Approximately $400 \mathrm{ng}$ of restriction enzyme-digested DNA was electrophoresed and transferred to Nytran $\mathrm{N}$ membranes (Schleicher \& Schuell, Keene, NH, U.S.A.). Probes were hybridized to the membranes and detected with a DIG DNA Labeling and Detection Kit (Boehringer Mannheim, Indianapolis, IN, U.S.A.) following the manufacturer's instructions. Southern hybridization of the genomic library was performed by standard techniques (Sambrook et al. 1989) with ${ }^{32} \mathrm{P}$ labeled probes prepared with an Oligolabelling Kit (Amersham Pharmacia Biotech, Piscataway, NJ, U.S.A.)

\section{Plasmid rescue.}

Restriction enzyme-digested genomic DNA was extracted once with phenol-chloroform, once with chloroform, and then precipitated with ethanol. One microgram of digested genomic DNA was recircularized in a $200-\mu 1$ ligation reaction consisting of two units of T4 DNA ligase (Life Technologies, Rockville, MD, U.S.A.) and the manufacturer's buffer. The ligation reaction was performed at $16^{\circ} \mathrm{C}$ overnight. The reaction was incubated at $65^{\circ} \mathrm{C}$ for $10 \mathrm{~min}$ and precipitated with 1 volume of sodium acetate and 2 volumes of ethanol, washed with $70 \%$ ethanol, and dried. The samples were dissolved in 5 $\mu \mathrm{l}$ of TE buffer and electroporated into SURE electroporationcompetent cells (Stratagene, La Jolla, CA, U.S.A.).

\section{PCR and DNA sequencing.}

Reactions were performed in $50-\mu 1$ volumes and consisted of $0.5 \mu \mathrm{M}$ of each primer, $0.2 \mathrm{mM}$ deoxynucleoside triphosphate, 0.6 units of Taq DNA Polymerase (Life Technologies, Rockville, MD, U.S.A.), and $1.5 \mathrm{mM} \mathrm{MgCl}_{2}$. The PCR buffer was supplied with the Taq enzyme. Thermal cycling was performed in a PE Applied Biosystems (Foster City, CA, U.S.A.) Model 480 Thermal Cycler with 30 cycles at $94^{\circ} \mathrm{C}$ for $30 \mathrm{~s}$, $55^{\circ} \mathrm{C}$ for $30 \mathrm{~s}$, and $72^{\circ} \mathrm{C}$ for $30 \mathrm{~s}$. The primer annealing temperature was optimized for each primer pair.
Sequencing reactions were performed with a PE Applied Biosystems BigDye Terminator Kit and analyzed on a PE Applied Biosystems Model 310 Genetic Analyzer.

\section{Stalk pathogenicity assays.}

The in vitro bioassay was adapted from one described by Nicholson and Warren (1976). Maize inbred Mp305 (Toman and White 1993) was grown in 10-in. pots in the greenhouse in a mixture of $1 / 2$ sterilized field soil and 1/2 Promix (Premiere Horticulture Ltd., Rivière-du-Loup, PQ, Canada). Plants were fed daily with a solution of $4.75 \mathrm{~g}$ of Miracle-Gro 18-18-21 formulation for tomatoes (Stern's Miracle-Gro Products Inc., Port Washington, NY, U.S.A.) per liter. Plants were harvested at a late vegetative stage (V-11) (Ritchie et al. 1993), and the first four internodes above the brace roots were recovered for use in the assay. The sheath was removed, and the internodes were cut into $2.5-\mathrm{cm}$ segments. The internode segments were rinsed under cold, running tap water for $1 \mathrm{~h}$ and then blotted dry on sterile paper towels. Each internode segment was wounded with a sterilized dissecting needle to a depth of $2 \mathrm{~mm}$. Suspensions of falcate conidia of C. graminicola or $C$. sublineolum were prepared by collecting conidia from 2-week-old cultures, washing them twice with water by centrifugation, and adjusting the suspension to $5 \times 10^{6}$ conidia per milliliter of water. A $10-\mu \mathrm{l}$ drop of conidial suspension was applied to the wound. C. sublineolum, a stalk rot pathogen of sorghum that is nonpathogenic to corn, was used in our experiments as a negative control. The inoculated internode segments were incubated in darkness at $30^{\circ} \mathrm{C}$ in moist, sterile chambers. After 3 days, they were split longitudinally, with the cut centered on the inoculation site. The area of the discolored region of pith under the inoculation site was measured. A small sample of pith tissue was isolated from an area on the opposite side of the stalk segment beyond the discolored region. The tissue samples were cultured on PDA plus $100 \mu \mathrm{g}$ of ampicillin per milliliter and observed for outgrowth of $C$. graminicola. If $C$. graminicola grew from the pith sample, it was considered to be colonized. Each REMI strain was tested twice in the preliminary assay. If both replications produced no significant necrosis, the isolate was retested in three separate experiments of five replications each in vitro and in intact plants in the greenhouse to confirm its phenotype. Isolates were retested in the replicated assays only if they produced necrotic symptoms that were less than $20 \%$ of the wild type in the primary assay.

The in vivo stalk assay was similar to the in vitro assay, except that the plants remained intact. The sheath tissue was stripped from the first four internodes above the brace roots. The plants were laid on their sides, and a wound was made near the center of the third internode above the prop roots, as was done for the in vitro assay. A $10-\mu$ drop of a conidial suspension of sterile water, prepared the same way as for the in vitro assay, was applied to each wound. A ring-shaped section of a sterile microfuge tube was placed over each spore droplet, and the wound site was sealed with Parafilm to create a humidity chamber. The inoculated plants were returned to their upright positions on the morning following the inoculation and incubated on the greenhouse bench for 3 days. The humidity chambers were left in place for the entire incubation period. At the end of the experiment, internode sections con- 
taining the wounds were recovered and treated in a manner identical to the in vitro assay.

\section{Leaf pathogenicity assays.}

We used two methods for the inoculation of leaves with $C$. graminicola. First, falcate conidia were collected from PDA plates grown under continuous light for 2 to 3 weeks. Suspensions of unwashed falcate conidia were prepared in water at a concentration of $10^{5}$ conidia per milliliter, and one drop of Tween 20 was added to each $100 \mathrm{ml}$ of suspension. The spores were applied to the leaves of V-3 seedlings with a chromatography atomizer (Nicholson and Warren 1976). In the second method, spores were applied directly from PDA cultures with a cotton swab onto the second and third leaves of V-3 seedlings, a technique adapted from Sweigard et al. (1998). In both methods, after inoculation the plants were placed in a mist chamber for $12 \mathrm{~h}$.

\section{ACKNOWLEDGMENTS}

We appreciate the excellent technical assistance of D. Brown, J. Takach, and R. Green. We are also grateful to C. Poneleit for allowing us to increase our maize inbred lines in his nursery plots. These studies were supported by NRI grant 97-35303-4968 from the U.S. Department of Agriculture. This is paper number 00-12-157 from the Kentucky Agricultural Experiment Station, published with permission of the director.

\section{LITERATURE CITED}

Bergstrom, G. C., and Nicholson, R. L. 1999. The biology of corn anthracnose: Knowledge to exploit for improved management. Plant Dis. 83:596-608.

Bölker, M., Böhnert, H. U., Braun, K. H., Görl, J., and Kahmann, R. 1995. Tagging pathogenicity genes in Ustilago maydis by restriction enzyme mediated integration (REMI). Mol. Gen. Genet. 248:547-552.

Epstein, L., Lusnak, K., and Kaur, S. 1998. Transformation-mediated developmental mutants of Glomerella graminicola (Colletotrichum graminicola). Fungal Genet. Biol. 23:189-203.

Gurr, S. J., Unkles, S. E., and Kinghorn, J. R. 1987. The structure and organization of nuclear genes of filamentous fungi. Pages 93-139 in: Gene Structure in Eukaryotic Organisms. J. R. Kinghorn, ed. IRL Press, Washington, DC.

Kahmann, R., and Basse, C. 1999. REMI (restriction enzyme mediated integration) and its impact on the isolation of pathogenicity genes in fungi attacking plants. Eur. J. Plant Pathol. 105:221-229.

Maier, F. J., and Shäfer, W. 1999. Mutagenesis via insertional- or restriction enzyme-mediated-integration (REMI) as a tool to tag pathogenicity related genes in plant pathogenic fungi. Biol. Chem. 380:855-864.

Ritchie, S. W., Hanway, J. J., and Benson, G. O. 1993. How a Corn Plant Develops. Iowa State University of Science and Technology Cooperative Extension Service, Ames, IA, U.S.A.

Sambrook, J., Fritch, E. F., and Maniatis, T. 1989. Molecular Cloning, A Laboratory Manual. 2nd ed. Cold Spring Harbor Laboratory Press, Cold Spring Harbor, NY, U.S.A.

Shi, Z., Christian, D., and Leung, H. 1995. Enhanced transformation in Magnaporthe grisea by restriction enzyme mediated integration of plasmid DNA. Phytopathology 85:329-333.

Sweigard, J. A. 1996. A REMI primer for filamentous fungi. Int. Soc. Mol. Plant-Microbe Interact. Rep. Spring:3-5.

Sweigard, J. A., Carroll, A. M., Farrall, L., Chumley, F. G., and Valent, B. 1998. Magnaporthe grisea pathogenicity genes obtained through insertional mutagenesis. Mol. Plant-Microbe Interact. 11:404-412.

Sweigard, J. A., Chumley, F. G., Carroll, A. M., Farrall, L., and Valent, B. 1997. A series of vectors for fungal transformation. Fungal Genet. Newsl. 44.

Toman, J., Jr., and White, D. G. 1993. Inheritance of resistance to anthracnose stalk rot of corn. Phytopathology 83:981-986.

Tuite, J. 1969. Plant Pathological Methods: Fungi and Bacteria. Burgess Publishing, Minneapolis.

Vaillancourt, L. J., and Hanau, R. M. 1991. A method for genetic analysis of Glomerella graminicola (Colletotrichum graminicola) from maize. Phytopathology. 81:530-534.

Vaillancourt, L. J., and Hanau, R. M. 1994. Cotransformation and targeted gene inactivation in the maize anthracnose fungus Glomerella graminicola. Appl. Environ. Microbiol. 60:3890-3893.

Vaillancourt, L. J., Du, M., Wang, J., Rollins, J., and Hanau, R. 2000. Genetic analysis of cross fertility between two self-sterile strains of Glomerella graminicola. Mycologia. 92:430-435.

White, D. G. 1999. Compendium of Corn Diseases. 3rd ed. American Phytopathological Society, St. Paul, MN, U.S.A.

Zuber, M. S., Ainsworth, T. C., Blanco, M. H., and Darrah, L. L. 1981. Effect of anthracnose leaf blight on stalk rind strength and yield in $\mathrm{F}_{1}$ single crosses in maize. Plant Dis. 65:719-722. 